\title{
Blockchain Technology: Revenue Streams of Long Tail Business Model
}

\author{
Fidiana Fidiana $^{1}$, Irwan Alnarus Kautsar ${ }^{2}$, and M. Ruslianor Maika ${ }^{3}$ \\ Accounting, Sekolah Tinggi Ilmu Ekonomi Indonesia,Surabaya, Indonesia ${ }^{1}$, \\ Informatics, Indonesia ${ }^{2}$ \\ Islamic banking, Indonesia ${ }^{3}$ \\ Universitas Muhammadiyah Sidoarjo, Sidoarjo, Indonesia ${ }^{2,3}$ \\ fidiana@stiesia.ac.id ${ }^{1}$,irwan@umsida.ac.id², mr.maika@umsida.ac.id ${ }^{3}$
}

\begin{abstract}
Blockchain technology is predicted to have a bright future as disintermediate of the financial institution become more popular. This research analysis the potential revenue streams through blockchain technology. However, the promising of disintermediation of their technology leaving turmoil all of start-up to release the decentralize system because of there is no revenue. We proposed long tail business model in term of release initial coin offerings (ICO) based on physical asset-backed of cryptocurrency. Rather than close platform to release ICO by the provider of cryptocurrency, we tends to open the platform to niche market like personal businessman, MSMS's or others to releasing their ICO. The result show many users of cryptocurrency make an ICO to raise funds and also many transaction of currency exchange occur in the platform. It look like high product of ICO with low of volume of funds but currency exchanges will often occur. Therefore, margin of currency exchange will made a new revenue streams for blockchain technology start-up to monetize their platform to shift to another stage of growth and stability.
\end{abstract}

Keywords: Blockchain Technology, Long Tail, Business Model, Revenue Streams.

\section{Introduction}

Blockchain technology is currently attracting great attention from public because the uniqueness of their technology characteristic as a foundation for disintermediate transaction [1]. The problem of double-spending in such as banks, notaries, escrow agents potentially replaced by blockchain technology [2]. Blockchain is a digitized decentralized ledger to allow record keeping of all peer-peer transactions without the need for a centralized authority [3]. Latest reviews of technical papers on blockchain research shows that the majority of scientific papers have focused on increasing and the challenge of the current Protocol, especially for cryptocurrency in General and particularly to Bitcoin [4].

The increasing of peer-to-peer platform like blockchain technology can't be denied and has changed the way for commercial transaction [5]. The main issue in developing of blockchain technology is the elimination of trusted parties [6], [7], [8]. Among the hype of that, the first question to answer the appropriate solution whether blockchain technology is the best technology to build peer-to-peer platform transaction trying to remove trusted parties such a 
bank [9]. Even multidisciplinary blockchain research framework about intermediaries tends to disseminating how blockchain technology could provide intermediary services [10].

There are three element of intermediaries function as the bank's core business, (1) rising funds, (2) make loans and (3) provide services. It was managed trillions dollars of global economy and takes trillions fee per transaction through system of slow payment, additional cost and takes more time [11], [8]. Finally, the customer bears the burden and opened over $45 \%$ per year of criminal opportunities from financial intermediaries activities include payment networks, money transfer and stock exchange [12]. It was worth estimated to save up sixteen billion dollars fees per year from Banking and Insurance transaction through smart contracts of blockchain technology [13] while others was estimated could reduce infrastructure cost $\$ 15-20$ billion per annum by 2022 [14].

Blockchain technology also was introduce new venture of raising funds through initial coin offerings (ICO) [15], [16], [17]. Coins are units of original value from the blockchain, therefore It is also important to distinguish between coins and tokens. The only purpose of a coin is to exchange values, and have limited functions beyond that [18]. Token is new type of digital assets that represent underlying of asset. At least, there are three taxonomies to understand of tokens [19]. First is currency tokens like Bitcoin that can be used to purchase goods and service. Second is platform tokens like Ethereum that provide a payment gateway and three is asset-backed tokens which is bound to underlying physical assets such as real estate, fine art, or even gold collections.

The promising of blockchain technology was envisioned as an online payment or platform tokens without trusted parties [6]. But many entrepreneur or start-up company difficult to choice about decentralized system that may release a fixed revenue streams [20]. This research aims to see the possible revenue streams from blockchain technology in term of disintermediate function of trusted parties. As a research methodology, we first define a framework to classify current activities of banking system and investigate possible activities of blockchain technology to acquire revenue streams.

\section{Literature Review}

The most important thing of disseminating new technology is about the adoption. The adoption of diffusion of innovation theory has four main elements include (1) an innovation (2) is communicated through certain channels (3) over time (4) among the members of a social system [21]. This theory was explain how idea and invention of technology will adopted through reducing uncertainty of a system over time [3]. Blockchain technology also need a decision making tool that will defining its technology as the correct perspective to reach disintermediate [9].

The rise of blockchain technology was marked by the operation of a peer-2-peer electronic cash system as known by Bitcoin [6]. It is outline the mechanism of new currency based on cryptography security system that will eliminating the trusted parties by online transfer to be sent directly from one party to recipient party [22]. Blockchain technology as one of the most enchanting research fields because the digital disruption has shaken financial services [23]. Whereas, level of analysis of multidisciplinary blockchain research fields is around (1) User and society, (2) Intermediaries, (3) Platforms, (4) Firms and Industries [10].

At least, there are five different activities between banking system and blockchain technology. First is payment when banking system offers an intermediary function in term of approving transaction between customers, while blockchain technology offers the anonymity of users [24]. Second is clearing and balancing systems. Users or customers takes more time to reconcile their transaction and also check their balance as an operating procedure of 
intermediary parties. Blockchain technology can reduce transaction time and simplifying of reconciliation process through real-time in clearing and balancing arrangements [22].

Third is get funding, if banking concept execute fundraising from customers whom excess funds through saving, Giro or time deposit product. Blockchain technology is trying to remodelling the business through initial coin offering (ICO). It may be characterized with the publication such as white paper or token sale term that contains detail information about price (pricing per coin), product (supply of token), place (IT adopted) and promotion (business plan and marketing team) to raise money through cryptocurrencies [25]. It is not only get funding from investor or customers but creating new opportunity from a broader access to capital.

The fourth is securities, the term of asset securities was shifted from non-asset to asset backed. When asset native is issued on-chain as a digital representation, it is called tokenising [8], [26], [27]. The last is lending or loan or credit by removing the necessity for gatekeepers within the lending business, the blockchain will build it safer to borrow cash and supply lower interest rates [8].

There is term that will confuse of blockchain researcher to clearly define about. The idea of distributed use to architecture, not for a policy of decision making [28]. Whereas decentralization is open network for everyone to access the ledger, identities are not recorded and the validation may lead decreasing speed of transaction [24], [9]. Blockchain is type of distributed ledger that is made out of a chain of cryptographically connected 'squares' containing bunched exchanges [27].

Before we examine potential revenue streams in discussion section, better we start to define what type of business model of blockchain technology. Business model is the art of how company to generate revenue and making profit [29], [30], [31]. In term of revenue streams, we found type of activities blockchain technology include infrastructure providers, application developers, and Operators [27]. Most revenue streams in one or more of the following ways [32], [27], [33].

Table 1. Revenue Model of Blockchain Technology

\begin{tabular}{|c|l|l|}
\hline NO & \multicolumn{1}{|c|}{ REVENUE MODEL } & \multicolumn{1}{c|}{ DESCRIPTION } \\
\hline 1 & Software as a service & Charging fee for using API and infrastructure \\
\hline 2 & Professional Services & Developing custom applications for enterprise clients \\
\hline 3 & Flat Fees \& Transaction Fees & Charging fee for subscription or fee per transaction \\
\hline 4 & Maintenance fee & $\begin{array}{l}\text { Charging for the maintenance of a distributed ledger } \\
\text { network codebase }\end{array}$ \\
\hline 5 & $\begin{array}{l}\text { Service Level Agreement (SLA) or } \\
\text { Premium support packages }\end{array}$ & Providing professional 24/7 support and training \\
\hline 6 & Consulting & $\begin{array}{l}\text { Providing consulting services to customers seeking to } \\
\text { adopt DLT: can range from ideation and the } \\
\text { development of a proof-of-concept to a full-production } \\
\text { deployment network }\end{array}$ \\
\hline 7 & A utility token & $\begin{array}{l}\text { It might be discharged which might be wont to access } \\
\text { the network or can even be listed inside the network. }\end{array}$ \\
\hline
\end{tabular}

\section{Method}

We use the long tail business model as a research approach in order to create a new opportunity of revenue model. The long tail concept was proposed by Chris Anderson in his book titled The Long Tail. It's concept is about selling that focusing on a large numbers of product with low volume (Anderson, 2006). We was defined in the section two the potential 
disruption of banking system including payment, clearing and balancing system, funding, securities, and lending with blockchain technology. After that, we try to investigate a new revenue model through long tail business model canvas (see figure 1).

To evaluate the business model canvas, we will arrange FGD and in depth interview with a stakeholder of the blockchain technology including 30 interviewee from Islamic Fintech Association, 4 interviewee from Otoritas Jasa Keuangan (OJK), 30 MSME's. The outcome of the method will describe a value proposition, customer segment and finally making a decision about the revenue streams. The revenue streams describe revenue generating from customer segment whom buy the value proposition of the product [30]. Revenue streams can take from two streams; (1) transaction revenue that come from one-time of payment, (2) recurring revenue that come from ongoing payment and re-purchase of others similar product.

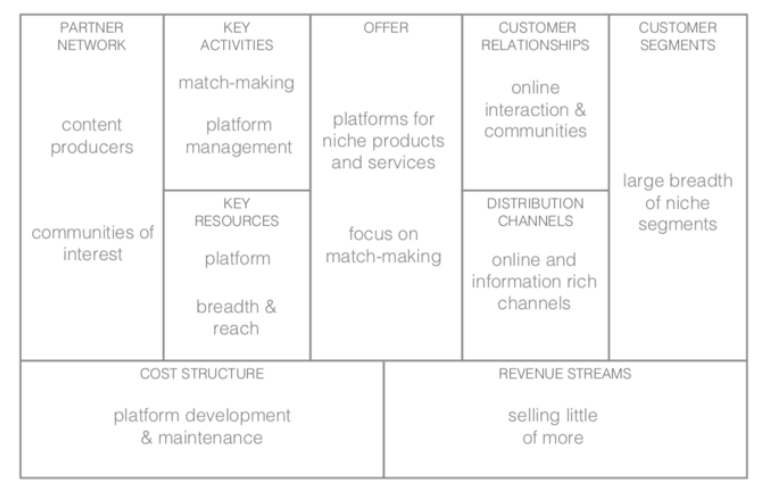

Fig. 1. Long Tail Business Model Canvas Concept

\section{Discussion}

The real challenge of commercialism niche content is finding interested potential consumers [30]. If we see the old model of music industry, the customer segment focusing on mass audience an match making with the value proposition from superstar artist and hits. While, the new model was open the platform did not focus on mass audience but switch to niche market like people who want buy or listen a song from another hits maker. Rather than entering the main market, our interviewee proposing to open a strategic avenue to pursue a "niche market strategy". Niche market is small market that consist an individual or a small group of customers with similar characteristics and needs [34].

Therefore, banking industries usually target mass market of funding customer and they also try to match making with the customer of lending product. They earn revenue streams from the deviation of lending margin and funding interest. Different from blockchain technology is reworking everything from payments transactions to however cash is raised within the non-public market [8]. As we mention above, blockchain can beyond question have an impact on just about each side of the financial set-up. Because it relates to banking and also the disruption we will expect to work out happening. Our research results show the initial coin offering (ICO) are mostly carried out by blockchain provider or operator and we proposed the initial coin offering offer by users. 


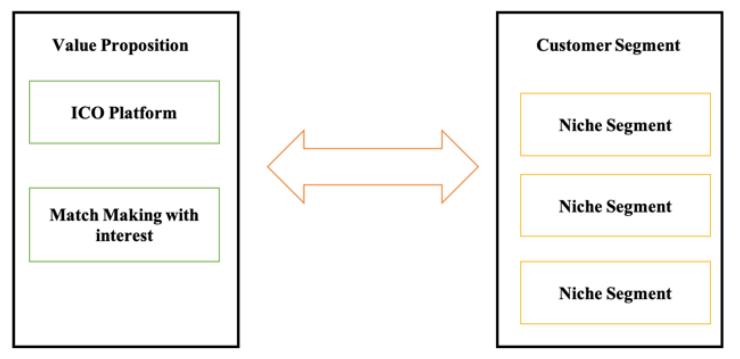

Fig. 2. Value Proposition Canvas

Initial coin offerings (ICOs) represent a completely unique mechanism for funding extremely innovative ventures that use distributed ledger technology (DLT) [16], [25]. ICO represent radical innovation in financial technology. In ICO, investors get the token directly from start-up; tokens unit is supposed to be the future of the venture project (for example, utilities, property rights, royalties) [16]. ICOs alter start-ups to lift massive amounts of funding with negligible effort whereas avoiding compliance and reduce intermediator cost [35].

Let we illustrate the value proposition canvas above. Nature of Initial Coin Offering (ICO) usually written in white paper document. It is a document in which the company provides the information deemed necessary for the public and is an important component of the campaign company ICO [36]. It mention the details of ICO total cap and distribution, legal and compliance, team, security, marketing and public relation, and also have within a maximum time of coin selling [37], [38]. While, Niche segment or one customer for example, stands as a home industry and needs some funding in term of rising of their working capital around 200 dollars. They open register in the Initial Coin Offering (ICO) platform and offering their equity crowdfunding to mass market about 50 coins. They start to campaign within a certain period to raise funds. It kind of online word of mouth and not just a peer-to-peer transaction or equity crowdfunding. It is an example of new economic model for raising working capital for home industry. If we compare with raise money through venture capital is a difficult process. Entrepreneurs have gathered with sat through countless meetings with partners, and last a long time in negotiations over equity and assessment in hopes of exchanging some part of their company for review. At blockchain, we do not need a platform to raise money. we don't need to venture capitalists. And also we do not need negotiations. All users can raise money from anyone at any time, and anyone can invest in their projects.

Indonesia still have gap financing about 988 trillion and over 49 million MSMEs unit not yet bankable [39]. World bank suggest there are between 365-445 million MSMEs in emerging country: 25-30 million are formal SMEs; 55-70 million are formal micro enterprises; and 285-345 million are informal enterprises. it was estimated $70 \%$ of all micro, small and medium enterprises in emerging country lack access to lending [40]. It may give large breath access of people, MSME's, home industry and or start-up company to rising funds through Initial Coin Offering. Quarterly report of cryptocurrencies was mention about $\$ 7,735,207,391$ amount raised from April - June 2018, include 339 Number of ICOs with the average amount raised over $\$ 22,817,720$ [41]. Only $18-20 \%$ of ICO that reach hard cap from April-June 2018 and numbers of cryptocurrencies provider in the world was recorded in www.coingecko.com over 3431. Our interviewees expected it might looks like one-third (small) of number of ICO will offers by cryptocurrencies provider in large volume and three- 
quarter (large) offers by users (MSME and personal) of cryptocurrencies in low volume in the future.

So where is revenue streams come from? Our interviewees estimated that ICO are fundamentally shift from seed fundraising to new investment ecosystem [42], [43]. It kind of mid of utility and equity token because represent ownership of an asset and also provide users with future access to a product or service. For example case study from cryptocurrency (assetbacked) like gold or Dinar and Dirham, when the crypto coin sold for currencies. It can represent ownership of the ingots and also enable the crypto coin to purchase for another product or services [44].

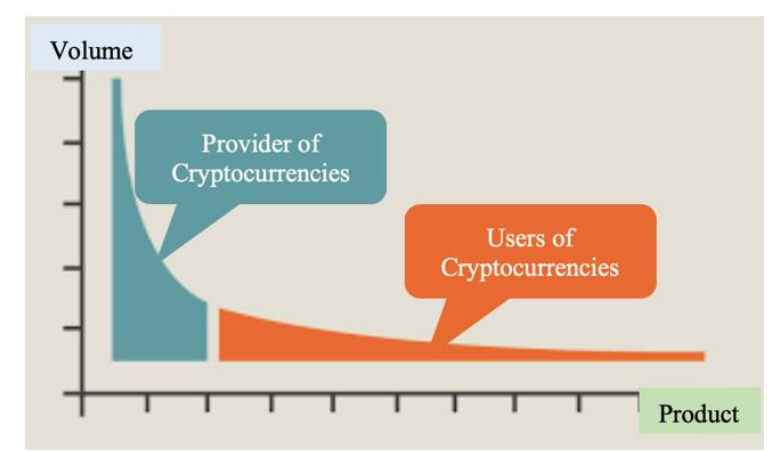

Fig. 3. Long Tail Business Model Projection

It is supposed to bring through individuals to exchange currency from fiat to gold or Dinar and Dirham. It additionally implies the model of revenue streams from fee based income to margin of currency exchange. Cryptocurrency may enable to provide price of sell and buy of the crypto coin in the website, normally buy price expensive from sell price because the difference in numbers indicate the margin of the exchange. This revenue model tends to comply with Islam because it is similar with the Ba' $i$ al-Sarf or currency exchange. But it may contradiction with the term and condition of purchasing gold via online. It should be cash transaction and handover directly and it was narrated that Ubadah bin As-Samit:

"Ubadah bin As-Samit and Muawiyah met at a stopping place on the road. 'Ubadah told them: 'The Messenger of Allah forbade selling gold for gold, silver for silver, wheat for wheat, barley for barley, dates for dates"'- one of them said: 'salt for salt,"' but the other did not say it-"unless it was like for like, hand to hand. And he commanded us to sell gold for silver and silver for gold, and wheat for barley and barley for wheat, and to hand, however we wanted." And one of them said: "Whoever gives more or ask for more has engaged in Riba."

But sharia Standard no 57 on Gold and its Trading Controls point 3/4 Sale of Gold Ingots for Currencies is the solution of the problem above. It cited following below:

"When gold ingots are sold for currencies, the counter-values must be exchanged during the contracting session. Possession of the ingot by the buyer, or his agent, is realized either physically or constructively. Constructive possession is realized by allocation of the ingot and by enabling the buyer to dispose of it, or by holding a certificate that represents ownership of a specified ingot that is distinguishable (an allocated ingot) from others, by serial numbers or other distinct marks from other ingots, provided the certificate is issued the day the contract is concluded [Trade Date "T+0”], by officially or customarily recognized agencies, enabling the buyer to take physical possession of the purchased ingot at his request" [45]. 
It impact the ICO usually launch by cryptocurrency provider with the low of numbers of product shift to ICO launch by cryptocurrency users with the high numbers of product. The important challenge of marketing niche content is finding interested potential patrons. Powerful search and recommendation engines, user ratings, and communities of interest have created this much easier. Many types of ICO products was indicated the high volume of currency exchange between fiat and cryptocurrency, even volume of each product is low.

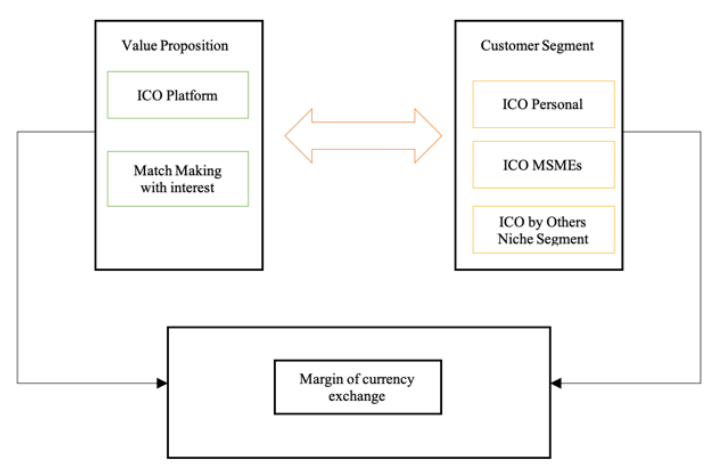

Fig. 3. Long Tail Business Model Revenue Streams

\section{Conclusion}

In this paper we tried to use a long tail business model as a model of revenue streams approach but still comply to Islamic. It may produce aggregate revenue or even exceeding revenues produced via long tail business model, because each currency exchange even in the first market of cryptocurrency will impact to the margin. It is also will eliminate the cost of intermediaries into free from the advantage of blockchain technology. Furthermore, the future research topics of ICO about the Islamic scheme of contract for the underlying asset as the asset-backed of the crypto coin.

\section{Acknowledgements}

Funding: This work was supported by Ministry of Research, Technology and Higher Education of Republic Indonesia.

\section{References}

[1] F. Glaser, "Pervasive Decentralisation of Digital Infrastructures: A Framework for Blockchain Enabled System and Use Case Analysis," Social Science Research Network, Rochester, NY, SSRN Scholarly Paper ID 3052165, Jan. 2017.

[2] M. Geranio, "Fintech in the Exchange Industry: Potential for Disruption?," Masaryk University Journal of Law and Technology, vol. 11, no. 2, pp. 245-266, Sep. 2017.

[3] J. M. Woodside, F. K. A. Jr, and W. Giberson, "Blockchain Technology Adoption Status and Strategies," Journal of International Technology and Information Management, vol. 26, no. 2, p. 30, 2017.

[4] F. Glaser and L. Bezzenberger, "Beyond Cryptocurrencies - A Taxonomy of Decentralized Consensus Systems," Social Science Research Network, Rochester, NY, SSRN Scholarly Paper ID 2605803, Mar. 2015. 
[5] F. Hawlitschek, B. Notheisen, and T. Teubner, "The limits of trust-free systems: A literature review on blockchain technology and trust in the sharing economy," Electronic Commerce Research and Applications, vol. 29, pp. 50-63, May 2018.

[6] S. Nakamoto, Bitcoin: A Peer-to-Peer Electronic Cash System. 2008.

[7] T. Dahlberg, "Mobile Payments in the Light of Money Theories - Means to Accelerate Mobile Payment Service Acceptance?," in Proceedings of the 17th International Conference on Electronic Commerce 2015, 2016.

[8] CBN, How Blockchain Could Disrupt Banking. 2018.

[9] B. Carson, G. Romanelli, P. Walsh, and A. Zhumaev, "Blockchain beyond the hype: What is the strategic business value?," 2018.

[10] M. Risius and K. Spohrer, "A Blockchain Research Framework," Bus Inf Syst Eng, vol. 59, no. 6, pp. 385-409, Dec. 2017.

[11] A. Tapscott and D. Tapscott, "How Blockchain Is Changing Finance," 2017.

[12] PwC, "Evolution Revolution," UK, 2014.

[13] S. Maity, "Smart Contracts in Financial Services: Getting from Hype to Reality," https://www.capgemini.com, 2016. [Online]. Available: https://www.capgemini.com/news/consumers-set-to-save-up-to-sixteen-billion-dollarson-banking-and-insurance-fees-thanks-to/\#. [Accessed: 28-Sep-2018].

[14] K. Petrasic and M. Bornfreund, "Beyond Bitcoin: The blockchain revolution in financial services | White \& Case LLP," 2016. [Online]. Available: //www.whitecase.com/publications/insight/beyond-bitcoin-blockchain-revolutionfinancial-services. [Accessed: 12-Oct-2018].

[15] P. Glazer, "Understanding Initial Coin Offerings (ICOs)," Hacker Noon, 24-Jan-2018. [Online]. Available: https://hackernoon.com/understanding-initial-coin-offerings-icosa61064170150. [Accessed: 11-Nov-2018].

[16] C. Fisch, "Initial coin offerings (ICOs) to finance new ventures," Journal of Business Venturing, Oct. 2018.

[17] C. Catalini and J. S. Gans, "Initial Coin Offerings and the Value of Crypto Tokens by Christian Catalini, Joshua S. Gans :: SSRN," Rotman School of Management, 2018.

[18] Z. LeBeau, "What's the Difference Between an 'ICO' and a 'Token Launch'?," Medium, 30-Dec-2017.

[19] J. Hargrave, N. K. Sahdev, and O. Feldmeier, "How Value is Created in Tokenized Assets," Social Science Research Network, Rochester, NY, SSRN Scholarly Paper ID 3146191, 2018.

[20] J. Bloomberg, "How To Make Money With Blockchain, Despite The Hype," https://www.forbes.com, 2018. [Online]. Available: https://www.forbes.com/sites/jasonbloomberg/2018/04/23/how-to-make-money-withblockchain-despite-the-hype/\#39b7728f4f60. [Accessed: 28-Sep-2018].

[21] E. M. Rogers, Diffusion of innovations, 3rd ed. The Free Press, 1962.

[22] Bank for International Settlements, Distributed ledger technology in payment, clearing and settlement, 1st ed. Basel, 2017.

[23] EY, "Chain reaction: how blockchain Technology Could Revolutionize The Finance Function," EY, 2016.

[24] A. Ludwin, "How Anonymous is Bitcoin? A Backgrounder for Policymakers," Coindesk, 2015. [Online]. Available: https://www.coindesk.com/anonymous-bitcoinbackgrounder-policymakers. [Accessed: 03-Jan-2019].

[25] S. Adhami, G. Giudici, and S. Martinazzi, "Why do businesses go crypto? An empirical analysis of initial coin offerings," Journal of Economics and Business, May 2018. 
[26] George S, “Asset Tokenization on Blockchain Explained in Plain English," Medium, 2018. .

[27] G. Hileman and M. Rauchs, "Global Cryptocurrency Benchmarking Study," University of Cambridge \& VISA, Cambridge, 2017.

[28] J. Bloomberg, "Enterprise Blockchain Struggles To Carve Out A Niche," Forbes, Sep2018. [Online]. Available: https://www.forbes.com/sites/jasonbloomberg/2018/09/09/enterprise-blockchainstruggles-to-carve-out-a-niche/. [Accessed: 11-Oct-2018].

[29] J. Magretta, "Why Business Models Matter," Harvard Business Review, no. May, p. 8, 2002.

[30] A. Osterwalder and Y. Pigneur, Business Model Generation. New Jersey: John Wiley \& Sons, 2010.

[31] A. Ovans, "What Is a Business Model?," 2015. [Online]. Available: https://hbr.org/2015/01/what-is-a-business-model. [Accessed: 12-Oct-2018].

[32] W. Vaughan, "How do blockchain businesses make money? - Quora," 2016. [Online]. Available: https://www.quora.com/How-do-blockchain-businesses-make-money. [Accessed: 12-Oct-2018].

[33] M. Lopez, "The Blockchain Business Model," Feedough, 2018. .

[34] M. Ottosson and D. Kindström, "Exploring proactive niche market strategies in the steel industry: Activities and implications," Industrial Marketing Management, vol. 55, pp. 119-130, May 2016.

[35] W. A. Kaal, "Initial Coin Offerings: The Top 25 Jurisdictions and Their Comparative Regulatory Responses," Social Science Research Network, Rochester, NY, SSRN Scholarly Paper ID 3117224, 2018.

[36] S. Cohney, D. A. Hoffman, J. Sklaroff, and D. A. Wishnick, "Coin-Operated Capitalism," Social Science Research Network, Rochester, NY, Working Paper ID 3215345, 2018.

[37] ICOcrowd, "Key Points for Evaluating ICO Investments," ICO CROWD - The Disruptive Investors Magazine, 2018. .

[38] A. Lielacher, "What Investors Should Know about ICO Best Practices - Bitcoin Market Journal," 2017. [Online]. Available: https://www.bitcoinmarketjournal.com/icoinvestment-returns/. [Accessed: 15-Oct-2018].

[39] Asosiasi Fintech Indonesia and DailySocialid, "Indonesia FinTech Report 2016," FinTech Indonesia \& DailySocialid, Jakarta, 2016.

[40] World Bank, "SME Finance," World Bank, 2017. [Online]. Available: http://www.worldbank.org/en/topic/smefinance. [Accessed: 15-Oct-2018].

[41] CoinGecko, "Quarterly Cryptocurrencies Report," CoinGecko, Quarterly Q2 2018, 2018.

[42] J. Wilmoth, "The Difference Between Utility Tokens and Equity Tokens," Strategic Coin, 2017. .

[43] G. Fridgen, F. Regner, A. Schweizer, and N. Urbach, "Don't Slip on the Initial Coin Offering (ICO) - A Taxonomy for a Blockchain-enabled Form of Crowdfunding," presented at the Twenty-Sixth European Conference on Information Systems (ECIS 2018), Portsmouth,UK, 2018.

[44] F. Fidiana, I. A. Kautsar, and M. R. Maika, "Blockchain Technology: Deep Shift from Islamic Perspective," 2018.

[45] AAOIFI, "Sharia Standard no 57 on Gold and its Trading Controls," 2016. 